\title{
The Shanghai Art School: Relocating Chinese Art Teaching from The Private Studios To The Public Education System, 1913-1937
}

\author{
Jane Zheng ${ }^{1}$ \\ ${ }^{1}$ BA Programme in Cultural Management, Faculty of Arts, Chinese University of Hong Kong, China \\ Correspondence: Jane Zheng, Rm201, BA Programme in Cultural Management, Faculty of Arts, Leung Kao Kui \\ Building, Chinese University of Hong Kong, Shatin, N.T., Hong Kong. Tel: 852-3943-4706. E-mail: \\ janezzn@hotmail.com
}

Received: February 8, $2013 \quad$ Accepted: February 21, $2013 \quad$ Online Published: November xx, 2014
doi:10.5539/ach.v7n1p164

\begin{abstract}
This article examines the role of modern art educational institutions that emerged in the early $20^{\text {th }}$ century China in transforming Chinese artists and their art, by comparing the manner of art teaching and other artistic activities in the traditional literati master's private studio and those found in the Shanghai Art School, an early and important art school in Republican China. The research draws upon a wide range of primary sources as well as secondary documents. It shows that when teaching in the public institution of the School, artists' teaching techniques were enriched, and their teaching psychologies were restructured. This article finally contributes towards an improved understanding of "modern" artists and "modern" art in China.
\end{abstract}

Key words: the Shanghai Art School, modern Chinese artists and art, public sphere

\section{Introduction}

For several decades the study of Chinese art history has focused upon exploring "modernity" in Chinese painting. Earlier scholarship examined the way that Western painting and culture were imported to China by returned Chinese artists and visiting Western artists. Scholars branded those Chinese paintings that incorporated more or less Western artistic elements as "modern". Conversely, paintings that followed the literati tradition were viewed as conservative or "traditional" (Kao, 1972; Sullivan, 1996). In the 1990s, a new perspective was used to examine the influence of the art world on its products which embraced "modern" artistic features. A consensus has been reached among art historians that the major transition in $20^{\text {th }}$ century Chinese art did not lie solely in the nature of the art itself, but also in the art world: institutions including magazines, museums, schools, dealers and auction houses that served the artists and their patrons, through which "modernity in its various guises" should be recognized ("Abstract of the 1999 AAS Annual Meeting" March 11-14, 1999). Jason C. Kuo points out that "the mass-produced calendar-posters from the 1930s and 1940s in fact embody Chinese modernity better than traditional Chinese painting" (Kuo, 2000, p.195). Julia F. Andrews and Kuiyi Shen note, "What it meant to be an artist in China was radically transformed" (Andrews \& Shen, 2002). Using this approach, a rising number of art historians have been exploring the Shanghai press or the publishing world and the mass circulated printed matters that they produced, such as books, magazines, periodicals and newspapers. Other articles examine the connection between Shanghai's urban social conditions and modern art (Hay, 2001, pp.61-101; Lee, 1989, pp.223-231; Andrews \& Shen, 2007, pp.79-94) and activities in the Shanghai art world (e.g. art societies and exhibitions) (Croizier, 1993, pp.135-154).

This research explores the art school that has hitherto attracted relatively limited scholarly interest as a medium of transformation in what it meant to be an artist. I have argued elsewhere that modern art schools played an important role in hastening artists' achievement of fame, deeply incorporating artists into the modern economic system and art market, and transplanting literati painting education from the private space to the public school system, resulting in a semiotic exhausted type of painting, guohua (traditional Chinese style painting) (Zheng, 2007; 2008; 2010). This article focuses on the teaching and administrative structure in art schools and compares artists' teaching styles and other related activities in private studios in the literati tradition and that found in modern art schools regarding the aspects of artists' art teaching purposes and skills, teaching psychologies and work capabilities. In terms of the traditional mode, this research uses Wu Changshi (1844-1927), Wu Hufan (1894-1968) and Feng Chaoran (1882-1954) as the main cases for comparison. These contemporaries of artists teaching in the 
Shanghai Art School were recognized as the most accomplished artists in the Republican Shanghai art world and they preserved the traditional literati style of life, painting and teaching at home. Based on the comparison, this research takes a further step to explore the influence of the transition of the milieu, from the private to public domain, on artists' art teaching and art practice. It examines the functions, artistic styles, techniques and subject matter of artworks. The research uses the Shanghai Art School (Shanghai Meishu Zhuanmen Xuexiao) (Note 1), an important early art school in China, scrutinizing the first half of the school's history in the Republican period. It draws widely on primary sources, including school archives and personal interviews, in addition to secondary materials (e.g. newspaper articles and published paintings), to shed light on the transformation of artists and their art. This article comprises four sections. The first section discusses the changes in artists' teaching styles and skills. The second section examines the transformation of teaching psychologies. The third is concerned with the impact of school administrative duties on artists' working capabilities and on society. The final section examines the transformations in artists' paintings related to artists' new roles in the public educational institution.

\section{Restructuring Teaching Styles and Techniques}

In the pre-modern era, private domestic spaces were the main venues of the Chinese artist's activities, including art practice, art teaching and private art gatherings with personal friends. Artists indulged in literati style painting as a means of escape from the chaotic political world (Fong, 1993, pp. 43-54). The increasing prosperity of the art market from the late Ming and Qing period had drawn artists into the public sphere to a degree with the selling and distribution system. Their art teaching and practice, however, was still confined to their private spaces. This situation changed with the emergence of modern art schools. In this section, I argue that the transition of the milieu of art teaching from private studios to the public art institution led to significant changes in artists' teaching styles and skills.

First of all, the School discarded the random and unscheduled teaching style of the master's private studio and developed a well planned, step-by-step teaching syllabus in order to benefit students' learning. In a master's private studio, there was no scheduled class. The time table depended on the master's living habits, leisure time and moods. For instance, the master Feng Chaoran painted only at midnight and slept in the daytime (Lu, 1986) 13. Therefore, students sometimes went to Feng in the early morning before he went to bed and sometimes at midnight (Private interview with Mr. Xu Lantai, Dec. 20,2001). Also, there was no clear teaching procedure. Lu Yanshao (1909-1993) recalled that when he first began his study with Feng Chaoran, Feng lent him a painting by Dai Jing (1388-1462) to copy at home (Lu, 1986, p. 13) (Note 2) instead of beginning by explaining brush and ink techniques or copying methods. This teaching method sometimes defeated the aspirations of students not sufficiently talented or not favored by the master. By contrast, the School established its own step by step teaching method with clear teaching goals to give students appropriate guidance (Meishu, 1918, p.12). In guohua teaching for example (Note 3), different teaching schedules that covered the basic guohua techniques and painting principles were discussed at the academic affairs meeting in the Chinese Painting Department in 1925. The agreed proposal was that three academic years would provide three stages of learning, from elementary to advanced. The Year One course included double sketches (mobi shuanggou) in the first semester, and washes and ink (shui mo) in the second semester. In the second year, students learnt how to copy masters' works from prior dynasties in fine and delicate brushstrokes (gongbi linggu) (semester one); and spontaneous brushwork (yibi linggu) and color application (semester two). In the third year, students were free to express themselves (SMZDA, Q250-1-40, 1925) (Note 4). The School teaching structure also included a feedback mechanism to make sure that students had really learned what the School expected. According to the School's regulations in 1924, students' studies (including painting practice, theory and history) were examined by the director of each department and each student was graded as "pass" or "fail" every week (SMZDA, 1924, p.69). In the final score report, four grades of A, B, C, and $\mathrm{D}$ (Note 5) were given.

Whereas excellence in drawing or painting was sufficient for an artist in his private studio, it was not enough to qualify as an art instructor in the art school. In other words, art teaching was more highly valued than simply the ability to paint well and all successful art instructors were versed in both teaching and painting skills. Pan Tianshou (1898-1971) for instance, achieved wide popularity in the School because of his talent in teaching (Liu, 1989, pp.25-29). Xie Gongzhan (1885-1940) also enjoyed a good reputation for teaching. Xie's peers commented that "No student will be poor at painting if he/she follows Mr. Xie. I do not only admire his paintings but also his talent in teaching" (Sun, 1918, p.4). Innovative teaching techniques in the School included demonstrating painting techniques, magnetic speaking techniques, body gestures and other public communication skills for educational purposes.

The demonstration of procedures in painting practice and techniques was not a major teaching technique in a master's private studio, and instruction to a great extent, depended on the master's mood. When privately taught by 
Feng Chaoran, Lu Yanshao went to Feng's house twice a month, showing Feng his copied works for Feng's comments. "When my works aroused his interest, he would correct several strokes for me" (Lu, 1986, p.12). Even when the student had a chance to stay at the master's home, it was still difficult for him to see the master painting, particularly during the first and second years. Wang Geyi (1897-1988) lived at Wu Changshi's as a private tutor of Wu's grandson Zhiyuan. He stayed on the ground floor, while Wu's living room and studio were located upstairs. $\mathrm{Wu}$ normally did not go down stairs and Wang was occupied with teaching affairs. "Only in very exceptional circumstances was I able to see Wu painting. I usually didn't go upstairs. In addition, I was there not for long and not as an acquaintance, so I did not have many chances to see him painting. In the presence of outsiders, he did not paint" (Wang, 1982, p. 39). By contrast, the School's education aimed to demystify painting techniques and to make each point clear enough for students to follow. Teachers in the School extensively employed the teaching technique of demonstrating painting techniques in didactic drawings. Lü Fengzi (1887-1970) (Note 6) for instance, liked to demonstrate brush techniques to students. When he painted, all the students gathered to observe. From the first stroke to the last, he painted while explaining the principles (Zheng, 1993, 208-212). He Tianjian (1891-1977) also considered this to be an effective way for students to understand the brush strokes (cun $f a$ ) in different classical schools of practice:

I demonstrated the repertoire of brush strokes from the bending stroke (gou zhe) of the Tang period to those developed in the Ming and Qing periods for comparison. I once asked the students if these (paintings practiced to show to students) could be viewed as living painting history? This helped students to understand different types of brush strokes (He, 1962, p.22).

Pan Tianshou was also a teacher proficient in using this teaching technique to inspire his students. Song Bingheng (1912-?), a graduate of the College, recalled a lesson in which Pan showed students the way to paint a floating spider web with faintly discernible curved lines. The gossamer in the spider web looked "both slender and light, which flies with the wind, discernible at one moment and gone at the next" and "all the students were stunned" (Song, 1989, pp.61-63). This teaching technique was also used to teach Western style painting. When Ni Yide (1902-1969) taught Guangdong students who were unable to understand his Shanghai Dialect, he mainly relied on the technique of demonstration. He was greatly respected by his Guangdong students (Ni, 1999, p. 144).

Moreover, in order to accurately convey points to students, language, body gestures and other methods which would have had little significance in the teaching in private studios, were frequently employed by school teachers. Liu Haisu's (1896-1994) free lectures once or twice every week were favored by students,

There was a wide range of topics: from art ideologies to artists' critical biographies, and from the Six Laws to Impressionism. Sometimes he also mentioned his personal experience in painting practice or the aim of running the school, seriously but with humor. Every student was deeply impressed by his lectures. When in an elated mood, he would keep on talking for two or three hours without appearing tired (Liu, 1981, p.97).

Xie Haiyan (1910-2001) was another art teacher who with vivid descriptions attracted his students in the first class. He used slide projection and gave detailed explanations of Greek mythology and Bible stories (Xu, 1988, pp.18-27). Jiang Danshu (1885-1962) was good at using gestures. When teaching Anatomy, he not only demonstrated using pictures, but also his own chest, arms and feet to give vivid lessons (Xie, 1991, p.5). By contrast, Wang Yuanbo (1905-1957), an eminent painter with Western style painting techniques, established personal style and a sound academic background in the Ecole Des Beaux-Arts, but attracted the least number of students to his classroom because he spoke little during his class, primarily due to his reserved character (Cai, 1999, p.14). Also, artists' other personal talents (e.g. calligraphy, poems and literature) were originally forms of intellectual entertainment in the literati tradition, but they began to have a communicative function in education. Students sometimes requested their teachers to compose colophons for their paintings and teachers improvised poems to stimulate students' interest in learning painting. Wu Fuzhi (1900-1977), for instance, composed poems as gifts to his students (Zhang, 1992). Lü Fengzi would delightedly compose comments for praising and glorifying students who had made good progress, urging them to study even harder (Zheng, 1993, pp. 208-212).

When art education moved from the masters' private studio to the public school, a new style of teaching was developed through the School. It was characterized by a well planned teaching schedule providing clear, step by step guidance and enriched teaching skills, which made art education more accessible to the public. 


\section{Reformulating Teaching Psychologies}

In the modern educational institution, artists' teaching psychologies were reformulated. Having a teaching position in the School enhanced the confidence of young artists as teachers and the teacher-student relationship and the inter-teacher relationship were re-formulated under the new working conditions in the public system.

At the school organizational level, young artists (young art teachers) who might not have been able to establish themselves as accomplished artists outside the School because of their limited social experience and youth were able to establish their reputations in the School. For instance, Liu Kang (1911- ) on his return from Paris was only 23. Too young to recruit private students; he was engaged by Liu Haisu as an instructor at the School. To begin with, Liu Haisu worried whether students who might be older than Liu Kang would accept his instruction (Liu, 1981, pp. 95-104). However, the teaching position gave him the chance to demonstrate his talents and teaching capabilities and he won the respect of his students.

On another level, the original ethics-based, master-pupil relationship was restructured in the school system, resulting in a new teacher-student relationship. In the private master-pupil mode, there was a stable and life long relationship between the master and his students as the saying goes, "One day being your teacher, the whole life being your father". Students living at the master's home, like Wang Geyi, were accepted as family members. Wang even took care of Wu Changshi's daily life (Wang, 1982, pp. 50-52). The majority of the essays written by students who personally followed masters recorded their unusual excitement when being accepted and showed deep respect and gratitude toward the master. Shi Chongpeng (?-?) recalled the experience of being accepted by the famous landscape master Xiao Zhiquan (?-?) (Note 7). After his graduation from the School, he hoped to pursue his landscape studies by following an outstanding landscape master. He was told that ordinary landscape artists in Shanghai were not always good painters; while eminent landscape painters would never accept students casually, so he felt unusually fortunate and happy when accepted by Xiao (Shi, 1948, p. 6). However, at the art school, it seemed that everything came as a matter of course. Students took the opportunities for granted and showed far less excitement and gratitude. If the teacher-student relationship did not continue in a personal mode after graduation, the relationship ended. Therefore, Jiang Danshu stated:

We teachers are just like wet nurses at nursery schools. When babies wish to suckle milk, they climb to our arms. Once they can eat rice, we are soon forgotten. After they grow up to be adults, perhaps they would not recognize who the old lady is. This is what Meng Zi called a trouble that people make for themselves if they like to be teachers of others. Therefore, as for the teacher-student relationship, I just let it run its own way. Zhuang Zi said, "Call me bull, I will answer as a bull; call me horse, I will answer as a horse". Logically, it is fine if you take me as your teacher and also fine if you do not take me as your teacher (Anon., 1947, p.6).

These words would have been incredible in the non-school era and it might have been the reason why many artists, although teaching a huge number of students at art schools were very cautious when taking private students. For instance, Lü Fengzi, famous for "Indulging in self-admiration" and "being above the vulgar", in his entire life adopted only one student, Xu Xingzhi (1904-1991), in spite of the large number of students he had taught at various art schools (Xu, 1986, pp. 32-36).

Also, the learning requirements were now not set solely by masters but were also influenced by students' reactions. In the master-pupil model, masters had absolute power in guiding students' learning; even if the comments were harsh, students and their parents dared not complain (Jiang, 1991). However, in the art school, responsible but strict teachers like Zhang Xian (?-1936) were criticized by students outside class: "Cold face, scolded me so severely!" "Yes, I lost my mood several days ago. It could have been tolerated even though my work was not good enough, but he criticized my work in this and that: everything was poor - it should be redone. What an inhumane person!" "This semester, Composition will be tested - this was also suggested by him. He even brushed aside others' opposing opinions. Now, we follow the same as students in Tokyo and Paris; we have to submit one more work: Composition" (Anon., 1933, p.4). These comments suggest that the original master-oriented, personal, emotional and ethically balanced relationship was changed in the School to a relationship, more open, but influenced by the public system which sometimes decreased the human kindness usually found in traditional Chinese ethics.

In addition to changes in the teacher-student relationship, the masters' inter-relationships were also restructured. Private friendship among masters (typically embodied in the literati's art and poetry gatherings) was now replaced by a public relationship characterized by cooperation and competition. In the group working environment, it 
became important for masters to be less occupied in displaying their personal talents, rather, giving more attention to cooperation with others. For instance, not all the teachers had the chance to give major courses; some artists taught minor courses. Jiang Danshu, for example, always taught minor courses, but this suited his purpose (Jiang, 1991, p.3). Others like Wang Yinqiu (?-?) and Ma Yulin (?-?) also taught minor courses such as handicraft at the School for 13 years (up to 1937). It is obvious that competition did exist among teachers. There was a case in the Western Painting Department where students selected the teachers they wanted to learn from and joined their studios thus creating competition among teachers in attracting students.

In summary, an artist's status was established by the school organization. The teacher-student relationship was regulated by the public system and the inter-masters' personal friendship was replaced by a public relationship. Based on these findings, the School reformulated artists' teaching psychologies.

\section{Conclusion}

This article aims to explore whether the transition of the teaching milieu from the private to the public domain influenced artists' teaching, teaching related activities, and their art, and if so, how. It compares the style of teaching art in the private studios of the literati with that in the modern school of art, using the Shanghai Art School as the case for study. It shows that when adapted to the new purpose of teaching, Chinese art teaching in the School was well organized and artists' teaching techniques were enriched: painting demonstration, body gestures and vivid explanations were used to convey teaching points. Teaching psychologies underwent change: young artists gained greater access to opportunities for becoming teachers, but the master-pupil bond featuring deep personal respect from students was cut, and the inter-master relationship was also transformed from private friendship to a cooperative and competitive relationship among colleagues. Based on these findings, this research argues that the teaching and administrative structure of the School played an important role in adapting artists to the public education system, enhancing teaching and social communication functions of their artworks and partly changing their artistic expression.

Thus, this research has served to improve the understanding of modern Chinese artists and their art. It confirms the argument of art historians such as Julie Andrews and Jackson Kuo that the main transformations lay in the art world in addition to artworks, and the art world embodied "modernity" to a greater extent than artworks. Modern art schools changed the purpose and the way of Chinese art education from teaching according to the whims of masters in their private studios to teaching for the public with greater accessibility of art education. This transition also involved the conversion of art from being the source of private, creative enjoyment for the literati in their studios, to a resource serving public institutions. In this sense, being "modern Chinese artists" means more than actively learning Western style painting, but is the adaptation to a new social structure and the needs of the public. Likewise, "modernity" in Chinese painting cannot simply be understood as the Western influences on Chinese painting styles and techniques. Rather, the emergence of some new functions or stylistic features was more often resulted from certain conditions of a restructured art world, as well as the new roles of artists. Complementing other arguments that I have presented elsewhere, i.e., the role of art schools in "modernizing" artists and art, this article particularly highlights the function of the teaching and administrative structure of the School in this aspect. Based on this, a set of newly recognized characteristics of Chinese artists and their art (e.g. teaching with a variety of effective skills, carrying out multi-administrative duties, and the social communication functions of Chinese paintings) can be understood as "modern", and closely associated with the teaching and administrative structure of art schools.

\section{Reference}

Andrews, F. J., \& Shen, K. Y. (2007). The Traditionalist Response to Modernity: The Chinese Paiting Society of Shanghai. In J. Kuo (Ed.), Visual Culture in Shanghai, 1850s-1930s (pp. 79-94). Washington, D.C.: New Academia Pub.

Anon. (2002). Nationalism and painting societies of the 1930s: Talk for urban cultural institu- tions in early 20th-Century China. Retrieved April 13, 2002, from http://mclc.osu.edu/rc//pubs/institutions/andrews.htm

Anon. (1933). Students' comments on Zhang Xian, cited in Ye Ma, Zhang Xian Lun (On Zhang Xian). In the $13^{\text {th }}$ Graduation Book, collected in the Shanghai Library. p.4.

Anon. (1947). Journalist's Interview with Jiang Danshu. In Y. C. Wang et al. (Eds.), "Master-pupil" Section in Minguo 36 Nian Meishu Nian Jian, Shanghai: Zhongguo Tushu Zazhigongsi, p.6.

Anon. (1999). "Abstract of the 1999 AAS Annual Meeting" March 11-14, 1999, Boston, MA Session 158: Modernity and Patronage in Visual Culture of Qing China, organizer: Kuiyi Shen. Retrieved from http:/www.aasianst.org/absts/china/c-158.htm. For further discussion, see AAS Annual Meeting, "Session 
77: Modern Institutions of Art in Republican China", abstracts of the 2005 AAS Annual Meeting, Hyatt Regency, Chicago, March 31-April 3, 2005, http://222.aasianst.org/absts/2005abst/chinac-77.htm.

Cai, R. (1999). Shanghai Ti Zi Jian de Shidai Fengxi (Fashions in the Age of "Garret" in Shanghai). Shijiazhuang: Hebei jiao yu chu ban she.

Croizier, R. (1993). Post-Impressionists in Pre-War Shanghai: the Jueanshe and the Fate of Modernism in Republican China. In J. Clark (ed.), Modernity in Asian Art (pp. 135-154). Broadway, N.S.W.: Wide Peony Press.

Fong, W. C. (1993). Tung Ch'i-chang and Artistic Renewal. In W. Fong (Ed.), The Century of Tung Ch'i-ch'ang 1555-1636 (no.1, pp. 43-54). Seattle: University of Washington Press.

Hay, J. (2001). Painting and the Built Environment in Late Nineteenth century Shanghai.In M. K. Hearn, \& J. G. Smith (Eds.), Chinese Art Modern Expressions (pp. 61-101). New York: the Metropolitan Museum of Art.

He, T. J. (1962). Xuehua Shanshui Guocheng Zishu (The Process of Studying Landscape Painting). Beijing: Renmin Meishu Chubanshe.

Jiang, D. S. (1991). Jiang Danshu Yishu Jiaoyu Zazhu (Jiang Danshu's Essays on Art Education). Hangzhou: Zhejiang Jiaoyu.

Kao, M. (1972). China's Response to the West in Art: 1898-1937 (Ph.D.), Stanford University.

Kuo, J. C. (2000). Discovering Chinese Painting: Dialogues with American Art Historians. Dubuque, Iowa: Kendall/Hunt.

Lee, S. Y. (1989). The Art Patronage of Shanghai in the Nineteenth Century. In C. T. Li et al. (Eds.), Artists and Patrons: Some Social and Economic Aspects of Chinese Painting (pp. 223-231). Lawrence, Kansas: the University of Washington Press.

Liu, H. S. (1989). Wangshi Yixi Huai A Shou (Recalling Pan Tianshou). In L. Xin (Ed.), Pan Tianshou Yanjiu (Studies on Pan Tianshou) (pp. 25-29), Hangzhou: Zhejiang Academy of Fine Arts.

Liu, K. (1981). Liu Haisu yu Zhongguo de Jindai Yishu (Liu Haisu and Modern Chinese Art). In L. Kang (Ed.), Liu Kang Wenji (The Anthology of Liu Kang) (pp. 96-104). Singapore: Educational Publications Bureau Pte Ltd.

Lu, Y. S. (1986). Lu Yanshao Zixu (Auto-biography by Lu Yanshao). Shanghai: Shanghai Shuhua Chubanshe. Meishu, 1918, no.1.

Ni, Y. D. (1999). Ji Jige Meishu Qingnian (About Several Young Art Students). In Y. Ni and Y. S. Dig (Eds.), Ni Yide Yishu Suibi (Random Art Essays by Ni Yide) (pp. 143-152). Shanghai: Shanghai Wenyi Chubanshe.

Shi, C. P. (1948). Ji Wushi Xiao Zhiquan Xiansheng (My Teacher Mr. Xiao Zhiquan). In "Master-Pupil Section.” In Wang Yichang et al. (Eds.), Minguo 36 Nian Meishu Nianjian (The 1947 Art Yearbook), p.6.

Song, B. H. (1989). Tong Pan Xiansheng Xiangchu de Rizi (Days together with Mr. Pan). In X. Lu (Ed.), Pan Tianshou Yanjiu (Studies on Pan Tianshou) (pp. 61-63).

Sullivan, M. (1996). Art and Artists of Twentieth-century China. Berkeley, Calif.: University of California Press.

Sun, Y. X. (1918). "Preface.” In G. Z. Xie, Xinti Caise Xiesheng Hua Jieshuo (Eds.), Accoutns for New Color Life Drawings. Shanghai: Shanghai Shangwu Chubanshen.

Wang, G. Y. (1982). Wang Geyi Suixiang Lu (Random Essays of Wang Geyi) Shanghai: Shanghai Shuhua Chubanshe.

Xie, H. Y. (1991). Preface. In Jiang Danshu, Jiang Danshu Yishu Jiaoyu Zazhu (Jiang Danshu's Essays on Art Education). p.5.

Xu, F. (1988). Yizhan Mingdeng (A Bright Light). Nanyi Xuebao (The Academic Post of the Nanjing Art Academy), pp.18-27.

Xu, X. Z. (1986). Huiyi Enshi Lü Fengzi dui Wo de Jiaoyu yu Peiyang (Recalling the Education from My Teacher Lü Fengzi). Nanyi Xuebao (The Academic Post of the Nanjing Art Academy) (pp. 32-36), Nanjing: Nanjing Art Academy.

Zhang, Y. J. (1992). Wu Fuzhi Zhuan (A Biography of Wu Fuzhi). Duoyun (Art Cloud), 34 (March): 82-86. 
Zheng, C. (1993). Feng Xiansheng yu Zhongguo Hua Jiaoyu (Mr. Feng and Chinese Art Education). In Lu Xin (Ed.), Zhejiang Meiyuan Zhongguohua Xi 65 Zhounian (Chinese Paintings of The Zhejiang Academy of Fine Arts: The Achievements in 65 Years) (pp. 208-212). Zhejiang Meishu Xueyuan Chubanshe.

Zheng, J. (2007). A New Ladder Leading to Celebrity: The Shanghai Art School and the Modern Mechanism of Artistic Celebrity (1913-1937). Art Criticism, 22(1), 7-28.

Zheng, J. (2007). The Shanghai Fine Arts College and Modern Artists in the Public Sphere (1913-1937). East Asian history, (32), 217-230.

Zheng, J. (2010). Transplanting Literati Painting into the Modern Art School System:" Guohua" Education at the Shanghai Fine Arts College, 1924-1937. Studies in Art Education: A Journal of Issues and Research in Art Education, 52(1), 34-54.

\section{Notes}

Note 1. The Shanghai Art School changed its name seven times during its history. Its final official title was "the Shanghai College of Fine Arts" (Shanghai Meishu Zhuanke Xuexiao). Its popular name from 1917 to 1931 was the Shanghai Art School (Shanghai Meishu Zhuanmen Xuexiao), adopted in this article. The School was founded by Wu Shiguang (1885-?). Liu Haisu became the School president from 1919 to 1952 . He is famous for an open dispute with the Warlord of Sun Chuanfang in the Nude Model Incident of 1926.

Note 2. Lu Yanshao was a private student of Feng Chaoran and later switched to Wu Hufan. He became an established artist with high reputation in contemporary Chinese art world.

Note 3. There was Chinese Painting Department that taught guohua and Western Painting Department teaching painting along the Euro-American academic lineage.

Note 4. "The record of the academic affairs meeting in the Chinese Painting Department on March 30, 1925", SMZDA, Q250-1-40. [SMZDA is abbreviation of Shanghai Meizhuan Dangan (Archives of the Shanghai Art School). They are collected in the Shanghai Archive House. The number followed is the archive number.]

Note 5. In Chinese, “jia, yi, bing, ding”, SMZDA, 1925, Q250-1-103.

Note 6. Lü Fengzi taught in the College, from 1921 to 1922, before Chinese Painting Department had been set up. Lü taught in the Western Painting Department and he also gave advice to students who were interested in guohua practice after class (Xu, 1986, pp.32-36).

Note 7. Xiao Zhiquan was a famous landscapist in the late Qing and Republican period. He participated in the earliest modern school art education in China for several decades. But he taught a very limited number of private students.

\section{Copyrights}

Copyright for this article is retained by the author(s), with first publication rights granted to the journal.

This is an open-access article distributed under the terms and conditions of the Creative Commons Attribution license (http://creativecommons.org/licenses/by/3.0/). 